Riesch, H., (2014) Why did the proton cross the road? Humour and science communication, Public Understanding of Science doi: 10.1177/0963662514546299

\title{
Why did the proton cross the road? Humour and science communication
}

\begin{abstract}
The use of humour in public discourse about science has grown remarkably over the past few years, and when used in science communication activities is being seen as a great way of bringing science to the public through laughter. However, barely any research has been published yet either on the often assumed beneficial learning effects of humour in informal science education, nor the wider social functions and effects of humour about science and how humorous public discourse about science can influence the public understanding of science and the science - society relationship. This research note reviews some of the literature on the psychology and sociology of humour and comedy and tries to apply some of its insights onto what effects humour might have when used in science communication. Although not intended to be anti-humour, this note attempts at least to start a more critical conversation on the value of humour in the communication of science.
\end{abstract}

\section{Introduction}

Humour and comedy as part of public discourse about science and science-based public culture has received remarkably little attention in either sociology of science, science communication or comedy studies, despite an apparent recent expansion of humorous science communication, science-based sitcoms, stand-up routines and other humorous public science events. This research note will look at studies in the fields of psychology, education and particularly sociological comedy research to theorise how humorous public discourse about science can affect the public understanding of science, and through looking at a few examples draw out some of the potential pitfalls in the use humour in science communication activities.

I will start by giving a brief overview of recent rise of science-humour in public life which will lead on to some of the issues that have, so far mostly in the informal literature, been raised about using humour in science communication. I will then look at empirical research in education, psychology and communication studies on the uses of humour for teaching and persuasion, before going into the sociology of humour and critical comedy studies on the sources and social roles of humour, such as stereotyping and identity construction. I will then apply some of the insights of the reviewed sociological literature to a small selection of examples of science-based jokes and science comedy and what it can tell us about how humour can shape public perceptions of science and scientists, and how that might point to potential pitfalls in the use of humour in science communication.

\section{Science comedy}

The past decade has seen a formidable growth of science-related comedy, at least in the UK. This can take several different forms. Sometimes scientists themselves engage in comedy: for example "Bright Club", a project developed at University College London and now also being initiated at several other UK universities, organises stand-up performances by academics in collaboration with professional comedians (Bright Club, no date); a similar initiative in Portugal has also turned scientists into stand-up performers as a science communication activity (Pinto, Marçal \& Vaz, 2013). Several established comedians such as Dara O'Briain have started using their own science background to insert a science theme into their performances (see his interview with Lewis, 2013) while others such as Tim Minchin align themselves to a wider science and skeptics movement 
without claiming special expertise as scientists (Austin, 2011). Popular science writing can also take on a comedic form, for example the humorous fantasy author Terry Pratchett has co-authored (with a team of professional science writers) a series of hybrid novels / popular science books (starting with Pratchett, Steward, \& Cohen, 1999).

Other forms of science-based comedy do not ostensibly have science communication in mind. The internationally commercially successful sitcom The Big Bang Theory does not, on the surface, seek to educate about science, though its success has resulted in bringing science and scientists into the general public discussion. As a result of this success, and because it had set itself the task to portray the featured science as accurately as possible, some science consultants and even actors working on the show see this as an excellent opportunity for bringing science to a wider public (Saltzberg, 2010; Russo, 2012). The sitcom has however also been criticised as potentially unhelpful for science communication for its stereotypical depictions of scientists (Sandpaw, 2010).

Despite these diverse incarnations of science based humour, remarkably little academic reflection on how humour can structure and influence the public understanding of science and the relationship between science and society, have yet taken place (next to Bell, 2011, and to a more limited extend Mulkay and Gilbert 1982, who will be discussed further below). Oliver Marsh (2013), writing on the LSE's "impact of the social sciences" blog, argues that, while his experience showed comedy to be an enjoyable vehicle for science communication, there are some structural problems with science humour that make it almost by definition somewhat unsuitable for communicating new ideas because the audience needs to have a certain amount of background knowledge already in order to "get" most science jokes. He also argues that stand-up science comedy performances by their nature rely on pushing an image about science that is at odds with the engagement paradigm of contemporary science communication: "one elite person elevated over an attentive audience, whose role is purely to respond as one mass by laughing, or being awestruck by the science".

\section{The effects of humour on science teaching and persuasion}

Humour is sometimes argued to be an effective way of communicating science (Bultitude, 2011). Pinto, Marçal \& Vaz (2013) have shown that the audience appreciated the science stand-up comedy they investigated, although they also note that members of the audience tended to be highly educated and therefore more sympathetic to and knowledgeable about science already. While science education is not the only reason why science communication activities exist (with the public engagement paradigm foregrounding critical discussion and informed dialogue between experts and publics), it is also still the case that for many people, education and even persuasion is still one of the primary goals of science communication, especially in areas that are not relevant to informing policy (Davies et al. 2009). Whether humour is generally a good vehicle for teaching and/or persuading about the value of science in informal science communication contexts has so far however not been extensively researched. In this absence, we can start by looking into studies on humour in educational settings, and the communications literature on the role of humour in persuasion.

Within formal education, although some studies have found an improvement in student learning when the learning environment is humorous, other studies have shown little or no effect (see the extensive review by Banas, Dunbar, Rodriguez, \& Liu, 2011). An explanation for these disparate results could be the fact that there are many different types of jokes that can be made in a classroom setting. Humour should be relevant to the classroom material and appropriate because offensive or disparaging humour can damage the instructor's credibility (Wanzer, Frymier, Wojtaszczyk, \& Smith, 2006). Because humour relies on ambiguities and interpretative flexibility, a message that might appear straightforward to the teller might have a different meaning to the audience.

Research on the effects of humour in persuasion has been conducted in advertising (Weinberger and Gulas, 1992), again with mixed findings; humour increases attention to a subject and source liking, but the results are unclear as to persuasiveness, "with certain types of humor contributing to persuasiveness in some circumstances but not in others" (Martin, 2007: 136), and thus the role of 
humour in persuasion is complex, depending on "the kind of processing (peripheral or central), and characteristics of the audience, the topic, and the source of the message" (Martin, 2007: 139).

Research on the effects of political comedy on engagement with and knowledge of current affairs has shown positive effects in specific circumstances (Feldman and Young, 2008; Baek and Wojcieszak, 2009), though in health communication, humour has also been found to be trivialising the intended health message (e.g., Moyer-Guse, Mahood, \& Brookes, 2007).

The evidence on the usefulness of humour in education and persuasion is thus rather mixed, with some positive results reported, but also a lot of qualifications on the types of humour and the specific circumstances in which it is being used, therefore we can conclude that humour needs to be used rather carefully if science education or persuasion towards the value of science is the aim of a science communication activity.

\section{Critical humour studies and science humour}

Traditionally, three general types of theories on humour have been proposed (see Morreall, 1983; Billig, 2005 for fuller accounts). "Superiority" theories hold that we find things funny when they implicitly assert our own superiority through the shortcoming of others. Thus we laugh at clumsy people falling over banana skins or foreigners with stereotyped undesirable attributes. "Incongruity" theories explain funniness through the unexpected incongruity that brings unrelated concepts together; the humour is produced through our surprise at the unexpected. Finally, "relief" theories explain why something is funny as the sudden release of pent-up energy; for example laughter can help in defusing awkward social moments or break taboos and inhibitions.

These three are not mutually exclusive and most contemporary humour theorists such as Billig, point out that there seems to be some measure of truth in all three. Applied specifically to science, incongruity has been used to explain jokes that rely on contrasting scientific and everyday language: in the "proto-jokes" analysed by Mulkay \& Gilbert (1982), incongruity is produced through imagining what a scientist really means when he/she uses the formal language of scientific writing. For example, when the scientist writes "It has long been known that...", he/she means "I haven't bothered to look up the reference" (Mulkay and Gilbert 1982: 593). Superiority meanwhile surfaces when for example "pseudo-scientists" are portrayed as stupid.

Beyond the consideration of what precise characteristic causes something to be funny and its social effects, there are also deeper sociological considerations to be made regarding the societal value of humour. Billig (2005) takes the approach of questioning the often assumed intrinsic goodness of humour, which he argues seems to have become a universally unquestioned background stance in contemporary society. Noting for example that possessing a good sense of humour has become an almost moral personality trait, Billig argues that the critical discussion of humour has become a difficult task for the academic.

Elaborating his own account of humour, Billig argues that humour and laughter, especially if directed at others, can serve the function of teaching social norms and values through embarrassing others. Through embarrassment the target of the laugher learns to conform to social rules and norms. The embarrassment function of humour exists for example in the laughter that parents direct at their children. Likewise political satire often tries to embarrass the elite, by pointing out hypocrisies and laughing at it in order to provoke embarrassment and thus - hopefully - a change in behaviour. In this vein, some skeptics' science humour can take the route of laughing at the silliness of perceived pseudo-scientists, and like political satire, often has a very explicitly formulated activist aim, such as Minchin's (2011) poem about his conversation with a new-age dinner party guest.

However, Billig also outlines how humour as a form of political action can also be counterproductive, because it can give a perception of suitable action having been taken which leads to complacency towards more effective action (see also Mulkay's 1988 assessment of the conservative effects of political satire in the sitcom Yes, Minister). This line of argument echoes Bakhtin's (1984) influential concept of the carnivalesque functions of humour, where the officially sanctioned folly of the carnival serves to reinforce the established order. The carnivalesque can also become a tool 
for science communication - in her analysis of the Horrible Science book series for children Bell (2011) argues that they produce a clear sense of anarchy and ridicule aimed at often stereoptypically portrayed scientists but which at the same time emphasises the epistemic authority of science, an effect she terms "irreverent deference".

Scientists' own appropriations of their negative stereotypes, for example the reclaiming of the traditionally derisive term "geek", can be seen as a "reverse discourse" (Weaver, 2010), where the targets of (in Weaver's analysis, racist) jokes and stereotyping seek to appropriate the offending vocabulary and "laugh back". This, as Weaver points out, is a strategy fraught with difficulties and possible unintended consequences as the essentially polysemic nature of humour can lead to audience interpretations that reinforce the stereotype rather than undermine it as intended. While reclaiming the geek as a positive identification in science humour may be intended to show up the essential ridiculousness of the stereotype, substantial parts of the audience may instead see their stereotypes confirmed (see also the "Alf Garnett syndrome", Pickering \& Lockyer, 2005).

\section{Stereotypes and social boundaries}

The function and social effect of a joke can depend on the social context in which it is being told. The joke

there are 10 types of people: those who understand binary and those who don't

is funny depending on the background knowledge of the listener. It relies on the visual pun and therefore incongruity that the number two written down in binary looks like ten in the decimal system. However, it also includes an implied social division between those who understand binary and those who do not, which aligns with the division between those who "get" the joke and those who do not. Listening to a joke can sometimes become a test, if we laugh we signal that we get the joke and are therefore part of the ingroup (though this comes with the danger of being found out if we laugh but did not actually get it), whereas if we fail to be amused we mark ourselves out as standing apart - either by not having enough of a sense of humour, or by not being educated enough to get it; this joke can therefore also be analysed with a superiority interpretation.

This example is fairly obvious because the social division is spelled out in the punchline. However we can spot similar issues in other jokes requiring special knowledge:

Why did the chicken cross the Möbius strip? To get to the same side

Again, "getting" the joke depends on knowing what a Möbius strip is, and thus implicitly divides those with a minimum education from those without.

This all then also points to another social function of humour, which is as a social identity marker that delineates the ingroup from the outgroups; therefore the joke functions not only because of the incongruity from juxtaposing a science concept with the usually irreverent chicken/road jokes, but also it more subtly relies on a superiority effect as the teller and the audience are included into the desirable knowledgeable ingroup. Mulkay and Gilbert (1982) analyse their proto-jokes (as in the example given above) as the incongruous switch between formal (empiricist) and informal (contingent) interpretative repertoires. A modern version of this joke was seen recently in the Twitter hashtag \#overlyhonestmethods (which was celebrated in sections of the press as a great piece of spontaneous science communication, see e.g. Lorch, 2013; Chivers 2013). It invited scientists to write a sentence of the methodology section of a scientific paper as it really happened, producing tweets such as:

We didn't read half of the papers we cite because they are behind a paywall (@devillesylvain, quoted by Lorch, 2013)

While the joke-work itself here may be produced by the incongruity of using an inappropriate 
interpretative repertoire, we can discern a social element here which relates to the essential "insider joke" nature and thus back to the examples I gave above. Although in this case it is probably not necessary to be a scientist to appreciate the joke, it nevertheless produces a sense of community of those who have to deal with the implied silliness of the formality of scientific publishing, bracketing out those who do not. As a marker of a wider scientific social identity, these insider jokes mark out the joker as part of the community, he or she can joke about this situation because they are part of the ingroup. Similar maybe to Bell's "irreverent deference", these jokes may function as ridiculing the officialness of scientific writing and as a clearly marked carnivalesque exaggeration of scientific life, they nevertheless foreground the actual business of science as something to be respected - it is the ridiculousness of scientific writing norms and in the above example institutional barriers such as insufficient library subscriptions that are being ridiculed as impeding the actual business of science, which is not under question itself. This effectively reinforces the epistemic authority of scientists who are battling against unscientific forces they satirise. However by depending on interpretative ambiguity, the carnivalesque is an inherently polysemic concept and these jokes can be read several ways - Lorch sees the hashtag as an endearing demonstration that scientists are human, whereas an uncharitable interpretation will be that scientists are unprofessional. If the joke above (or most of the other contributions to \#overlyhonestmethods) had been made within the context of the "climategate" email leak (Nehrlich, 2010), reactions would have been different.

Jokes therefore can have a community and identity building aspect which depends on the situation and the social context in which the joke is being made and understood as much as the content of the joke itself; they are community building within social groups but potentially divisive between them.

Jokes that directly rely on stereotyping also abound in science-based comedy. Science comedy can easily fall into ridiculing people who do not like or understand science as stupid or uninteresting, playing on the superiority aspect of humour. Such negative stereotypes will fairly obviously not be the best vehicle for science communication if the aim is outreach towards the ridiculed group.

Scientists and their sympathisers on the other hand also get routinely caricatured, usually as geeks who are clever but socially awkward, and who are obsessed with comic books and Star Trek. Both ingroup and outgroup stereotypes are found for example in the sitcom The Big Bang Theory, which as noted above, has been touted by participating scientists as a great science communication tool. The sitcom centres on a group of friends working as university scientists (mostly physicists), plus one stereotypical "dumb blonde" outsider. The scientist main characters are socially awkward (to the extreme that one character, Sheldon Cooper, has been interpreted as playing on "disability humour", May, 2013) and are actively participating in science fiction fandom and other stereotypically geeky activities (Bednarek, 2012). In this portrayal of the scientist as clever but geeky, the show has found some resonance with physicists, who see Sheldon Cooper as no worse than an "exaggerated version of a physicist for comic effect" in an admittedly unscientific Facebook poll for Physics World (Johnston, 2011), the membership magazine of the UK's Institute of Physics.

In such comedic representations of scientists, their quirks and foibles are intended to be endearing and the scientists, socially awkward, naïve and madly coiffured, are nevertheless the heroes of the story. Superficially unflattering stereotypical accounts can have the effect of appealing to the community that is being stereotyped, fostering further social cohesion among the insider group and thus function similarly to the "insider" jokes discussed above.

A text however can be read several ways and essentially polysemic comedic texts that rely on ambiguities and interpretative flexibility especially so. Though the stereotypical portrayal of scientists can be seen and intended as a positive for those on the inside as being essentially part of the funny side of science, it can at the same time confirm negative stereotypes of people who are not invested in a science group identity.

\section{Tentative conclusions}

Using insights particularly from the sociology of humour, I have tried to argue that humour in 
public portrayals of science can have effects on the science-public relationship that may not always be benign or helpful to the cause of public engagement (if that is the aim). Humour can set up and often strengthen boundaries, by either fostering ingroup cohesion through insider jokes and the construction of reverse-dialogue re-appropriations of the geek stereotype or by excluding imagined outgroups through negative stereotyping. It is also not entirely straightforward whether humour as an intentional tool for either persuasive or educational goals is particularly effective, and it would have to at least be used very carefully.

Through the examples in this research note I hope to open up a discussion on the use of humour in science communication and public engagement, not so much because all the examples given are intentional public engagement activities, but because they exemplify some of the potential pitfalls that humour in public engagement could also easily fall into. This note is aimed at conceptualising what some of these pitfalls may be by referring to the sociology of humour. The next step will be to perform a full series of studies on the various incarnations of comedy in science communication in light of this theoretical background, adding audience reactions and performer opinions to textual analysis.

\section{Acknowledgements}

Many thanks to Sharon Lockyer and Simon Weaver and the Brunel Centre for Comedy Studies Research, as well as Oliver Marsh and the anonymous reviewers for their helpful comments on the paper.

Austin, K. (2011). Tim Minchin uses comedy to open a door to rationalism. New Scientist Culture Lab Blog, retrieved from: http://www.newscientist.com/blogs/culturelab/2011/11/timminchin-uses-comedy-to-open-a-door-to-rationalism.html

Baek, Y. M., \& Wojcieszak, M. E. (2009). Don't expect too much! Learning from late-night comedy and knowledge item difficulty. Communication Research, 36(6), 783-809.

Bakhtin, M. (1984). Rabelais and his world. Bloomington: Indiana University Press.

Banas, J. A., Dunbar, N., Rodriguez, D. \& Liu, S. (2011). A review of humor in educational settings: four decades of research. Communication Education 60(1), 115-144.

Bednarek, M. (2012). Constructing 'nerdiness': Characterisation in The Big Bang Theory. Multilingua 31(2), 199-229.

Bell, A. R. (2011). Science as 'horrible': irreverent deference in science communication. Science as Culture 20(4), 491-512.

Billig, M. (2005). Laughter and ridicule: Towards a social critique of humour. London: Sage.

Bright Club, (no date). About Bright Club. Retrieved from http://brightclub.wordpress.com/

Bultitude K (2011) The why and how of science communication. In P. Rosulek, Science Communication. Pilsen: European Commission.

Chivers, T. (2013). \#overlyhonestmethods reveals the silly side of science. The Daily Telegraph, January 9. Retrieved from:

http://www.telegraph.co.uk/science/9790120/overlyhonestmethods-reveals-the-silly-side-ofscience.html

Davies, S., McCallie, E., Simonsson, E., Lehr, J. \& Duensing, S. (2009). Discussing dialogue: perspectives on the value of science dialogue events that do not inform policy. Public Understanding of Science 18(3): 338-353.

Feldman, L and Young, D.G. (2008). Late-night comedy as a gateway to traditional news: an analysis of time trends in news attention among late-night comedy viewers during the 2004 presidential primaries. Political Communication 25(4):401-422.

Johnston, H. (2011). What topic will win this year's Nobel? Physics World, September 29. Retrieved from: http://blog.physicsworld.com/2011/09/29/what-topic-will-win-this-years/

Lewis, T. (2013). Dara Ó Briain: 'I could have done science but I became a clown instead'. The Guardian, September 15. Retrieved from: http://www.theguardian.com/culture/2013/sep/15/dara-obriain-interview 
Lorch, M. (2013). Scientists take to Twitter to reveal their less than scientific methods. The Guardian, January 10. Retrieved from: http://www.theguardian.com/science/blog/2013/jan/10/scientists-twitter-methods

Martin, R. A. (2010). The psychology of humor: An integrative approach. London: Elsevier Academic Press.

Marsh, O. (2013). A Funny Thing Happened On The Way To The Laboratory: Science and Standup Comedy. Retrieved from http://blogs.lse.ac.uk/impactofsocialsciences/2013/07/12/a-funnything-happened-on-the-way-to-the-laboratory/\#author

May, S. (2013). Comedy on the spectrum: An interview with Asperger's Are Us. Comedy Studies 4(1), 103-110.

Minchin, T. (2011). Storm!!!!!!!! Retrieved from http://www.timminchin.com/2011/04/08/storm/

Morreall, J. (1983). Taking laughter seriously. Albany: State University of New York Press.

Moyer-Gusé, E., Mahood, C., \& Brookes, S. (2011). Entertainment-education in the context of humor: effects on safer sex intentions and risk perceptions. Health Communication, 26(8), 765-774.

Mulkay, M. (1988). On Humour: Its Nature and Place in Modern Society. Cambridge: Polity Press

Mulkay, M. \& Gilbert, G. N. (1982). Joking apart: some recommendations concerning the analysis of scientific culture. Social Studies of Science 12(4), 585-613.

Pickering, M. \& Lockyer, S. (eds) (2005). Beyond a joke: The limits of humour. Palgrave Macmillan. Basingstoke: Palgrave McMillan.

Pinto, B., Marçal, D. \& Vaz, S. G. (2013). Communicating through humour: A project of stand-up comedy about science. Public Understanding of Science, doi: 10.1177/0963662513511175

Pratchett, T., Stewart, I. \& Cohen, J. (1999). The science of discworld. London: Ebury Press.

Russo, G. (2012). Turning point: Mayim Bialik. Nature, 485, 669.

Saltzberg, D. (2010). Physics and the Making of "The Big Bang" TV Comedy Series. Bulletin of the American Physical Society, 55.

Sandpaw (2010). The Big Bang Theory: a science in fiction backflip? Retrieved from: http://sandpaw.weblogs.anu.edu.au/2010/10/07/the-big-bang-theory-a-science-in-fictionbackflip/

Wanzer, M. B., Frymier, A. B., Wojtaszczyk, A. M. \& Smith, T. (2006). Appropriate and inappropriate uses of humor by teachers. Communication Education 55(2), 178-196.

Weaver, S. (2010). The 'Other' laughs back: humour and resistance in anti-racist comedy. Sociology 44(1), 31-48.

Weinberger, M. G., \& Gulas, C. S. (1992). The impact of humor in advertising: A review. Journal of Advertising, 21(4), 35-59. 